\title{
Las agencias internacionales de noticias como fuente de información audiovisual
}

\author{
Jorge Caldera Serrano \\ María Victoria Nuño Moral \\ Felipe Zapico Alonso \\ Universidad de Extremadura (España)
}

\subsection{Resumen}

Se presenta, describe y analiza la información audiovisual proporcionada por las agencias de noticias internacionales desde el punto de vista documental, mostrando las diferentes peculiaridades físicas y formales que la definen como fuente de información para las empresas televisivas. Las agencias analizadas han sido Eurovisión, Associated Press y Reuters. Se ha valorado tanto la información aportada por las cabeceras de los envíos como la calidad de las imágenes.

Palabras clave: Fuentes de información. Agencias de noticias. Información audiovisual. Archivos de televisión.

\subsection{Abstract}

The audiovisual information provided by the international news agencies is presented, described and analyzed. Their different physical and formal peculiarities as sources of information for the television companies are considered. The agencies analyzed are Eurovision, Associated Press and Reuters. Headlines and leads information power as well as the quality of images has been assessed.

Keywords: Information sources. News agencies. Audiovisual information. Television archives.

\section{Introducción}

Los procedimientos de acceso a la información en los medios audiovisuales son tan diversos como la realidad social en la que se ubican y trabajan dichas empresas comunicativas. Las fuentes de información son seleccionadas y contratadas atendiendo a criterios periodísticos, sin contar con referencias documentales, ya que las fuentes deben ser herramientas para el acceso a la información de actualidad conforme a criterios tales como su presencia en el mercado, competencia, coste y veracidad informativa. 
Las fuentes de información audiovisuales se dividen tradicionalmente en internas y externas; clasificación que define aspectos tan relevantes como la explotación comercial y la reutilización de las imágenes. Desde los departamentos de documentación se debe asumir el control de las peculiaridades referidas a los autores, productores y propietarios de los derechos de emisión de las imágenes, información que hay que tener en cuenta siempre que se analice una fuente externa a la propia organización.

Las fuentes internas son aquellas generadas por el propio medio. Por lo tanto, cumplen exactamente la ley del principio de procedencia de la Archivística, pues son generadas por la institución en el transcurso de su actividad, orientada por los objetivos de la empresa. Están constituidas por el material grabado por los reporteros gráficos de la empresa, además de las imágenes procedentes de los centros territoriales (también denominados delegaciones), corresponsalías, enviados especiales y de los propios archivos.

Las fuentes externas, por su parte, están constituidas por el material procedente de las agencias de intercambio, agencias de noticias, productoras audiovisuales, diferentes cadenas informativas, free lancers, así como por los recursos captados por personas anónimas que son testigos de un hecho informativo. Para un análisis más exhaustivo sobre las fuentes audiovisuales televisivas, se recomienda la consulta del artículo de Caldera y Zapico (2001). Dentro de esta segunda clase de fuentes - las externas - , el trabajo que se desarrolla desea mostrar las peculiaridades y características que definen la documentación audiovisual recibida por los medios televisivos procedente de las agencias de intercambio y las agencias de información, atendiendo, además, a los aspectos relacionados con las características físicas que exigen un tratamiento documental específico.

\section{Las agencias de información}

Cuando Napoleón murió en Santa Elena en el año 1821 los franceses se enteraron meses más tarde de su funeral. En 1963 la muerte del presidente Kennedy fue conocida por los estadounidenses y el mundo entero en varios minutos, y los atentados contra el Word Trace Center de Nueva York fueron transmitidos en directo por, prácticamente, la totalidad de las cadenas. Esta agilidad y facilidad de acceso a la información audiovisual está haciendo real lo profetizado por MacLuhan, convirtiendo nuestro planeta en una aldea global donde todo es conocido de forma rápida. Este intento de globalización, en este caso teledirigido, cuenta evidentemente con ventajas derivadas de la universalización y globalización informativa, motivada por los esfuerzos de las agencias informativas en la venta y distribución de la información, favorecidos tanto por el desarrollo tecnológico como por el crecimiento de los grandes medios de comunicación. 
Las agencias de noticias (también denominadas agencias de información) se han convertido en una fórmula habitual de acceso a la información de carácter internacional por parte de los medios nacionales, las cuales pueden definirse como empresas de comunicación que trabajan para otras compañías de comunicación realizando el envío continuo y permanente de hechos noticiosos acaecidos en ámbitos no accesibles por los medios. Entre las diferentes definiciones que existen aportamos la siguiente: "son organizaciones que recogen hechos, noticias, de sus corresponsales en distintos lugares de su área de actividad y las transmiten inmediatamente a la central, donde, después de tratar la información, la envían, lo más rápido posible, a sus clientes, conocidos en el argot periodístico como abonados" (Rodríguez Alonso, 2004).

La génesis de las agencias de información fue la unión entre diferentes periódicos con objeto de compartir recursos. El comienzo fue difícil. El desarrollo tecnológico, especialmente de la telegrafía en un primer momento y después de la emisión vía satélite, fueron aspectos más que relevantes en la evolución de las agencias, cuyo accionariado, por otra parte, suele estar presente en muchas cadenas privadas y grupos de comunicación de ámbito internacional. Una de las premisas que garantizan la supervivencia de estas empresas es la calidad, tanto desde el punto de vista físico - calidad facilitada por medio de la señal por satélite - como de la selección que ofrecen a sus asociados. Cuentan para ello con una gran capacidad de análisis de la realidad supranacional, que les sirve de base para una válida contextualización de los hechos informativos. Las agencias deben ser objetivas y veraces en la información suministrada a los medios, y llevar a cabo una selección informativa que nada tenga que ver con los matices ideológicos de la empresa audiovisual. Se ha de suministrar información a un conjunto de medios de dispar condición ética, política e ideológica, por lo que el tamiz de la agencia vendrá determinado en la selección de la información y no en la valoración del material suministrado.

Como se ha señalado con anterioridad la principal fuente de acceso de información de carácter internacional en las grandes cadenas son las imágenes que tras acuerdos contractuales llegan a las televisiones por medio de las agencias de información. Y es que las redes estables de corresponsalías como los enviados especiales constituyen una grave carga económica para las entidades audiovisuales; pero, además, se demuestran ineficaces e incapaces de acceder a la totalidad de la información, al ser su presencia imposible en todos y cada uno de los lugares donde ocurre un hecho noticioso. Por ello, los corresponsales únicamente obtienen información audiovisual preparada y presentada a partir de previsiones, y resulta complicado el acceso a información de actualidad. Éste es el vacío que llenan las agencias de información, facilitando noticias que en muchas ocasiones son presentadas como propias por parte de las diferentes cadenas cuando real-

Scire. $10: 2$ (jul.-dic. 2004) 137-146. 
mente son propiedad de dichas agencias de información. También cuentan con su cuota de mercado en el ámbito estatal, siendo su importancia cada vez mayor para aquellas televisiones, como las locales, que no cuentan con estructuras fijas de centros territoriales. Las agencias nacionales - EFE, Europa Press, Atlas y Colpisa - y otras de carácter autonómico - como Vasco Press con sede en Bilbao y Vitoria-Gasteiz, la catalana Intracatalonia con sede en Gerona, la agencia gallega Galicia Press, y ACN-Press con sede en las Islas Canarias - son la que cuentan con mayor presencia en el ámbito audiovisual español. Sin embargo, su utilización es mínima por parte de las grandes cadenas, las cuales acceden a la información a través de los profesionales que las propias empresas tienen repartidos por la geografía española.

Además, conviene distinguir entre las agencias de intercambio y las agencias de información. Las primeras no son agencias, sino redes de cooperación basadas en la existencia de un acuerdo entre diferentes medios para el intercambio de recursos. Estas agencias, desarrolladas para optimizar los recursos económicos de las empresas, deben contar con una buena base de partida por parte de los medios que la forman, pues tienen que ser capaces de servir información de suficiente calidad y valía para que pueda ser emitida por el resto del sistema. La agencia de intercambio más conocida en nuestro ámbito es Eurovisión, creada por la Unión Europea de Radiodifusión que forman las televisiones públicas estatales de Europa. Dicha agencia, actualmente con sede en Ginebra, distribuye la información por línea, información que previamente ha sido enviada por dichas cadenas. Aunque no pueda denominarse propiamente una agencia de intercambio, cabría mencionar a la Federación Oficial de Radio Televisiones Autonómicas (FORTA), formada por las cadenas autonómicas de nuestro Estado. Éstas intercambian información y productos informativos completos, abaratando así los costes de producción. Por el contrario, las agencias de noticias o agencias de información propiamente dichas no intercambian material de manera gratuita, sino con un fin lucrativo. Mediante acuerdos con cuotas millonarias, las agencias se comprometen a enviar material audiovisual sobre una temática definida y en horarios prefijados, concertando a priori los envíos. No obstante, es obvio que la actualidad es imposible preverla en su totalidad con anterioridad, por lo que los envíos sufren modificaciones atendiendo a la realidad informativa en un alto porcentaje de ocasiones.

\section{Características de las cabeceras de los envíos}

En este apartado se analizan las características de los envíos correspondientes a tres agencias: por un lado, la agencia de intercambio Eurovisión y, por el otro, dos de las agencias de información más importantes de ámbito mundial, a saber, la estadounidense Associated Press en su división de televisión (APTN) y

Scire. $10: 2$ (jul.-dic. 2004) 137-146. 
la británica REUTERS. Las agencias analizadas no difieren en absoluto en sus características visuales y técnicas. Las diferencias estriban en elementos estéticos derivados de la forma de entender y hacer televisión, lo que aparece reflejado en el manejo de los planos y la composición. En este trabajo no se pretende llevar a cabo un análisis semiótico de la información de agencias, sino tan solo de los aspectos formales que determinan su conservación, difusión y reutilización por parte de los medios de comunicación.

La agencia de intercambio Eurovisión, que posee acuerdos con otras agencias de información, cubre geográficamente todo el continente europeo, y distribuye información generada por el personal de las empresas estatales audiovisuales. Los envíos llegan en horarios prefijados, con el fin de poder captar debidamente dichos recursos en los soportes documentales. Toda la información de la agencia se ingresa en el sistema de información documental audiovisual, una vez ha sido analizada periodísticamente por la sección de internacional. Los envíos, por bloques temáticos, vienen precedidos por una cabecera que ofrece las áreas de información que se comentan a continuación. Su austeridad (figura 1) llama la atención si se compara con los ejemplos posteriores. En una primera columna, viene la numeración de las noticias, que es más o menos correlativa ya que pueden ir "surgiendo" noticias o desarrollándose otras a lo largo del propio envío. Igualmente, se observa la fecha del envío, así como la hora en la que comenzará la difusión de las imágenes, para así facilitar el envío multiseñal o broadcast. Además, se indica el origen de las imágenes, tanto la cadena que ha cedido el material como aquéllas que han servido de intermediarias para la difusión por la agencia de intercambio europea. En lo referente a la información temática, se ofrecen un conjunto de palabras claves en inglés que ayudan, con mayor o menor fortuna, a conocer el contenido de la información. El envío posterior se lleva a cabo con una cabecera

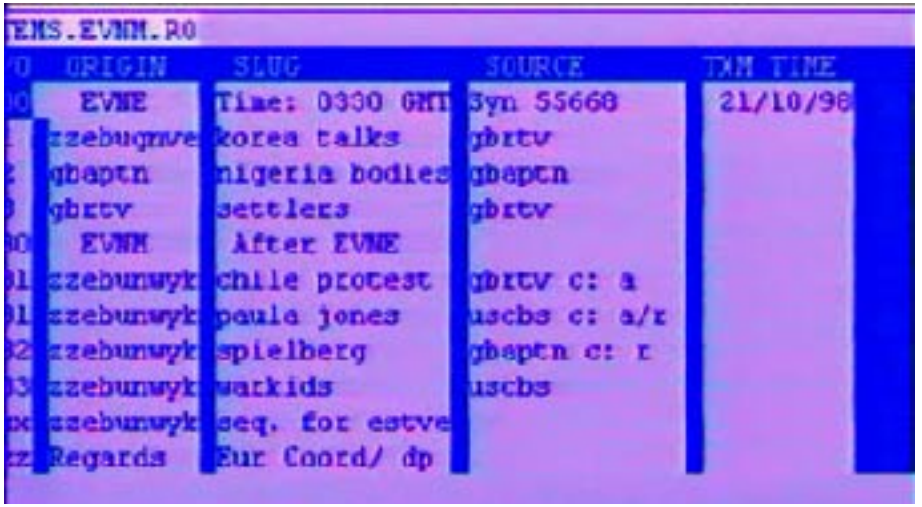

Fig. 1. Envío de la agencia Eurovisión por noticia muy similar a la utilizada por Reuters, que se estudiará después. El material, de duración variable en función de las características de la noticia, normalmente cuenta con un denominador común, a saber,

Scire. $10: 2$ (jul.-dic. 2004) 137-146. 
su origen europeo, aunque también se ofrece material informativo geográficamente distante, derivado de los acuerdos de Eurovisión con otras agencias de intercambios y agencias de información.

La segunda agencia analizada es la norteamericana Associated Press, que nació de la unión de seis diarios neoyorquinos que, con el fin de intercambiar información, crearon una "cooperativa informativa" para compartir el elevado coste del acceso a la información. Tras diferentes denominaciones, a finales del siglo XIX toma su nombre actual, y en la actualidad constituye, sin lugar a dudas, una de las agencias más importantes del mundo. La cabecera de la sección de noticias (Associated Press Television News) de la división de Televisión (APTV) de Associated Press es claramente más espectacular que la mostrada con anterioridad por parte de Eurovisión. Incluso el tiempo destinado a la conexión es mayor, en parte por la necesidad de vender una imagen corporativa y una buena presentación, otrosí de cubrir una serie de segundos de emisión, ya que en la mayor parte de los casos los servicios de estas agencias se contratan por tiempo de imágenes, y por lo tanto, del envío. Dichos envíos llegan precedidos, al igual que en el caso de Eurovisión o Reuters, de señales acústicas que sirven para comprobar la validez tanto de la banda imagen como de

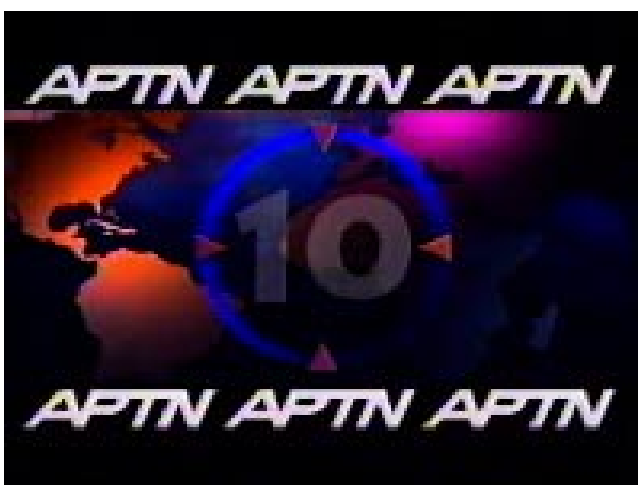

Fig. 2. Cabecera promocional de la APTN

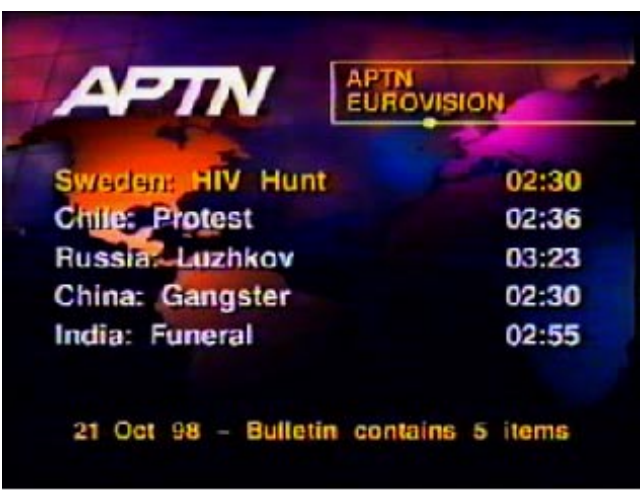

Fig. 3. Listado de noticias de la APTN

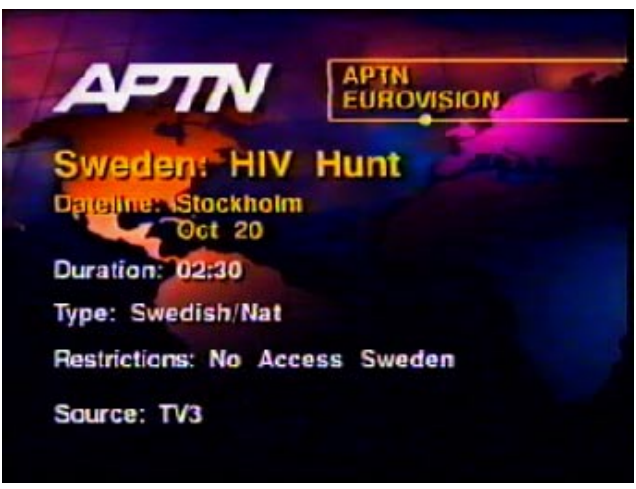

Fig. 4. Pantalla de noticias de la APNT

Scire. $10: 2$ (jul.-dic. 2004) 137-146. 
la banda sonido. El envío por satélite plantea graves problemas en la recepción de las imágenes, por lo que hacer a lo largo del proceso un seguimiento para valorar el estado de ambas bandas informativas. Como puede observarse, tras la cabecera promocional de la agencia (figura 2), aparece una pantalla informativa que señala el número de noticias enviadas así como la fecha del envío del material (figura 3). Se ofrece información de cada uno de los bloques informativos, señalándose en primer lugar el país, seguido de una palabra clave que intenta condensar la información sobre su contenido. En último lugar, se indica la duración de las imágenes de ese ítem informativo. Pero APTN no sólo incluye esta información a modo de sumario, sino que desarrolla cada una de las noticias aportando una mayor cantidad de datos tal y como se observa en la figura 4. La información que presenta es más completa desde el momento en que se informa sobre el país y palabras claves que identifican el contenido temático, la ciudad y fecha de captación de las imágenes (no confundir con la fecha del envío), la duración de las imágenes, el idioma de la locución o del sonido ambiente, y, finalmente, aspectos relacionados con los derechos de explotación y de reutilización.

La última cabecera analizada corresponde a la agencia británica Reuters, la cual comparte la hegemonía mundial con APTN. Al igual que en el caso anterior, Reuters personaliza las cabeceras atendiendo a la temática informativa. Así, la información bursátil, económica, política, y deportiva cuenta con diferentes cabeceras promocionales. Sin embargo, la información ofrecida posteriormente es idéntica en su estructura y formato (figuras 5 y 6 ). Estos dos primeros ejemplos que se muestran informan, en primer lugar, de acontecimientos que se desarrollan en directo y cuyos derechos para ser emitidos como tal pueden ser adquiridos. El segundo de ellos informa de los diferentes envíos que va a llevar a cabo la agencia, mencionando tanto la hora como el nombre del boletín. En este segundo caso

\section{REUTERS :}

1315 SPORTS DAILY

1330 WORLD NEWS

1415 SHOWBIZ DAILY

1500 GERMAN NEWS 2

1540 WORLD EXTRA

Helpdesk +44171542 2244 13:14 GMT

Fig. 5. Listado de noticias de Reuters (ejemplo 1)

\section{LIVE Event REUTERS 踝}

1555gmt ex French Guiana European Space Agency

to launch Ariane 503

scheduled to lift off at

1600 gmt.

Heipdesk +44171542 2244 $\frac{13144 \mathrm{GMT}}{21}$

Fig. 6. Listado de noticias de Reuters (ejemplo 2)

Scire. $10: 2$ (jul.-dic. 2004) 137-146. 


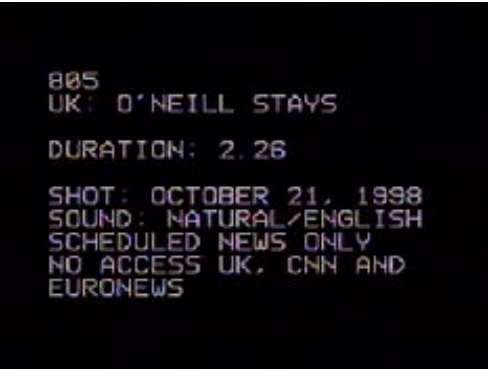

Fig. 7. Referencia de la noticia en Reuters (ejemplo 1)

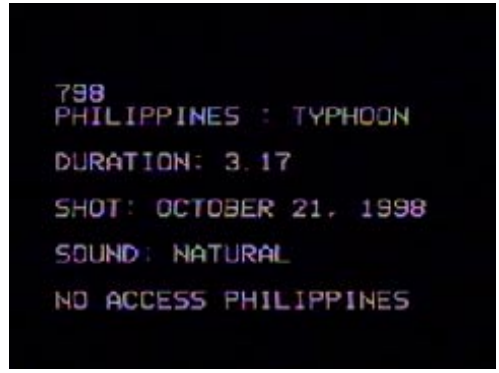

Fig. 8. Referencia de la noticia en Reuters (ejemplo 2)

expuesto, se puede observar como se producen cinco envíos diferentes en breve espacio de tiempo. Igualmente, en la parte inferior, se aprecian tanto el número telefónico de la agencia como la fecha y hora exacta. Los envíos comienzan con extremada y cuidada puntualidad. Los datos que se ofrecen sobre cada una de las noticias que componen los bloques de envíos anteriores son los mismos que los de la agencia APTN: en primer lugar, el número de la noticia (despacho de agencia); después, el país, una palabra clave que la describe, la duración de la información en minutos y segundos, la fecha del envío, y las características del audio - en el caso del ejemplo, se indica que cuenta con sonido natural-; finalmente, las condiciones de acceso y derechos del material - los ejemplos señalan la exclusión de acceso a la información audiovisual por parte de algunos medios y/o zonas geográficas-.

\section{Características físicas generales del material de agencia.}

El material de cualquier agencia internacional cuenta con una serie de peculiaridades que lo definen e individualizan frente al material procedente de otras fuentes de información. Desde el punto de vista temático y geográfico cabe referirse a la universalidad de los envíos, aunque la cobertura geográfica se centre muy especialmente en Europa y Norteamérica. Los diferentes matices que definen al material vienen condicionados por dos cuestiones generales y claramente diferenciables: el canal - satélite - y la estructura informativa.

Los despachos audiovisuales de agencia son materiales que suelen llegar montados o semimontados a las cabeceras de las cadenas, por lo que en sí mismos conforman una unidad documental informativa, ya que pueden ser emitidos tal y como los envía la agencia internacional. Ello es facilitado por el hecho de que carecen de rotulación de marca de cadena y de elementos de postproducción o grafismo que puedan servir para identificar su procedencia. Así, el material semi- 
montado - con una duración que oscila entre los dos y los seis minutos - puede ser cortado para adaptarlo al tiempo de emisión del Informativo y montado con la locución de la propia cadena y los elementos gráficos que identifican a la emisora. Por este motivo, puede difundirse como material propio, intercalado con la información de enviados especiales o de corresponsales fijos en el extranjero. En lo que respecta al sonido, hay que mencionar la existencia de sonido ambiente en la mayor parte de los envíos. Su ausencia - poco deseada, pues deja las imágenes "huecas" - suele ser atribuible a problemas de envío o recepción por parte del satélite, causa prácticamente de la totalidad de los casos con problemas físicos de señal. Aunque no suele ser norma habitual, el material de agencia puede contar con declaraciones, pero siempre realizadas por personajes de alto interés general, ya que deben adaptarse a las necesidades del conjunto de las cadenas antes que en las especificidades de cada uno de los medios que contratan los servicios.

La gestión documental de este material no difiere en nada de las imágenes procedentes de otras fuentes. Se extraen descriptores geográficos, onomásticos, temáticos y cronológicos para poder acceder a la información, datos que se duplicarán para indizar y recuperar tanto la banda imagen como la sonora. Cabría reiterar que el tratamiento documental nunca se ha de realizar sobre el material emitido por la cadena, sino sobre el original de la agencia. La información consignada durante el análisis formal y de contenido del material de agencia no es diferente de otras informaciones que llegan al medio, y se debe integrar en una única herramienta documental informatizada. En dicha herramienta se deben consignar una serie de parámetros tanto para el control de la información como para designar los diferentes puntos de acceso.

Los despachos de agencia cuentan con la particularidad de que no son únicos e irremplazables, a diferencia de lo que ocurre con las imágenes procedentes de otras fuentes que integran el archivo como el material bruto o aquél captado por los enviados especiales. En caso de pérdida, destrucción o descarte inicial de las imágenes $-\mathrm{y}$ subsiguiente borrado-, siempre se podrá acceder nuevamente a él volviendo a pagar por dicho material a la agencia, ya que ésta sí que conserva todos sus despachos audiovisuales. En cualquier caso, en los acuerdos contractuales entre la cadena y las agencias deben quedar especificados los derechos de explotación y reutilización, tanto en el momento presente como futuro, dejando constancia en el registro documental que identifica a las imágenes de cualquier tipo de incidencia o restricción sobre dichos aspectos.

\section{Conclusiones}

En primer lugar, conviene resaltar la preponderancia del material de agencia para satisfacer las necesidades visuales y contextualizadoras de las televisiones nacionales en la sección de internacional. Esta preponderancia en la información

Scire. $10: 2$ (jul.-dic. 2004) 137-146. 
internacional viene motivada por su universalidad temática y amplia cobertura geográfica, que evita la necesidad de contar con redes estables en el extranjero, abaratando así los costes de producción.

Los despachos audiovisuales son enviados a los medios en horarios prefijados. Además, se ofrece en cualquier momento la información de radiante actualidad, cortando la emisión de otros envíos si es necesario.

La información aportada por las agencias, aunque escasa para la descripción del material audiovisual, sí que está prácticamente estandarizada, y muestra los aspectos geográficos - lugar de la acción -, temáticos - palabras en texto libre que identifican su contenido-, físicos - duración - y legales - restricciones de acceso a la información-.

Las peculiaridades físicas de este material vienen marcadas por su duración - entre dos y seis minutos - y la ausencia de elementos visuales que personalicen la señal; es decir, la información no cuenta con elementos de postproducción, gráficos ni logotipo de la cadena que permitan identificar la procedencia, lo que ofrece la posibilidad de que dicho material sea emitido por las cadenas como si se tratara de material propio.

Sin lugar a dudas, el material de agencia es vital para una cobertura geográfica y temática universal por parte de los archivos de televisión, siendo necesario contar con políticas claras de adquisición, selección, tratamiento y conservación del mismo, y, en definitiva, considerarlo un activo más en el marco de las empresas comunicativas audiovisuales.

\section{Referencias}

Caldera Serrano, Jorge; Zapico Alonso, Felipe (2001). Principales fuentes de información audiovisual en las televisiones estatales. // Anales de la Documentación, 4, 2001. 39-50.

Rodríguez Alonso, Carmen Clara. Las agencias de información. // Peinado Miguel, Fernando (coord.). Media Prensa. Ministerio de Educación y Ciencia, CNICE, 2004. $<$ http://iris.cnice.mecd.es/media/prensa/bloque7/pag1.html>. 